\title{
La Filosofía de José Antonio Ramos y su Afinidad con la del Pueblo y los Pensadores de los Estados Unidos
}

Tos libros de José Antonio Ramos son libros de batalla. Yo no me atrevería a recomendarlos a quien busque en la literatura el solaz, el olvido de los diarios problemas o las satisfacciones puramente estéticas. Pero yo los recomendaría a todo latinoamericano que haya alguna vez sentido, por experiencia o por simpatía humana, la necesidad de una revisión de los valores de su cultura.

Queda así sugerido que los libros de Ramos continúan, en forma de novela, de teatro, de crítica o de ensayo, el proceso iniciado desde los albores de nuestra independencia nacional por los intelectuales hispanoamericanos contra la filosofía de la vida florecida en América de la cepa de España. En este proceso Ramos está al lado de Alberdi, Sarmiento, Bilbao, Lastarria, los que primero exhibieron la filosofía del pueblo norteamericano como contraste y remedio para Latinoamérica.

Dos aspectos, uno crítico y otro constructivo, parecen constituir la filosofía de Ramos: el antitradicionalismo y la noción del valor moral del trabajo manual.

Refirámonos, en primer lugar, al antitradicionalismo. Como espectros de una edad pretérita, los principios de la tradición hispánica desfilan en las obras de Ramos con una realidad de pesadilla: los prejuicios de casta, el desprecio al trabajo manual, el paternalismo despótico en la familia y en el Estado, el parasitismo de las clases altas, del clero y de la gente de espada, el fanatismo religioso, el falso idealismo legalístico y formulista, el control de la Iglesia en la educa- 
ción, la mojigatería de la mujer y el donjuanismo de los hombres. Contra estos fantasmas de la tradición que convierten la tierra latinoamericana en una anacrónica copia de la vida española del tiempo de la conquista y que sería cómica si no fuera trágica, por la mucha injusticia, maldad y miseria que encierra, Ramos ofrece un remedio: el trabajo; y un ejemplo: la prosperidad material y el progreso espiritual de los Estados Unidos.

Hace un siglo casi, Alberdi y Sarmiento hicieron una idéntica diagnosis del mal de Hispanoamérica y prescribieron idéntico remedio. Como Ramos, también tenían ellos la misma convicción del poder dignificador dél trabajo material, y como el se sintieron atraidos por el ejemplo del país en que esta convicción se ha hecho carne de la vida del pueblo que lo habita.. Por mucho tiempo, sin embargo, las voces de nuestros primeros filósofos fueron silenciadas en las escuelas por los gobernantes temerosos de perder sus privilegios. Generaciones de latinoamericanos fueron desposeídas así del legítimo derecho de conocer a sus más altos pensadores. Felizmente hoy las cosas han cambiado en muchos de los países hispánicos. Las obras de otros intelectuales, venidos del campo de la novela, de la crítica, del ensayo, se leen sobre todo por su conciencia social, mientras las de nuestros primeros pensádores comienzan a publicarse en México, Buenos Aires y Santiago. Ellas complementarán en parte un vacío notable en la producción de los escritores recientes. Falta en la mayoría de éstos el aspecto constructivo que los primeros pensadores nunca se olvidaron de agregar a su demoledora crítica de la vida hispanoamericana.

La actual literatura de tendencia social se resiente así de un exceso de diagnosis de nuestros males y de una lamentable deficiencia de ideas para encararlos. De esta deficiencia, sin embargo, se salva Ramos, aunque con riesgo de convertir su obra literaria en ensayos filosóficos; y así añade a su crítica del tradicionalismo un elemento constructivo, que es la apología del trabajo como base de la dignidad del hombre. De sus obras, dos son, a mi ver, las que mejor expresan su filosofía: una novela, Coaybay, y una obra de crítica, Panorama de la literatura norteamericana. En ambas se advierte con evidencia la admiración de su autor por los Estados Únidos, y la gran afinidad que la filosofía de Ramos tiene con la filosofía del pueblo norteamericano y la de sus filósofos profesionales. 
Coaybay es la historia de una revolución cubana, destinada a derrocar a un antiguo tirano, un generalote ignorante y brutal, que ha comprometido el crédito de la nación hasta un punto en que sus partidarios, la Banca y el ejército, consideran ruinoso para sus propios intereses. Misteriosamente, alguien asesina al tirano. Los mismos personajes que antes apoyaron al caído eligen ahora, con el fin de manejarlo a sus anchas, a un antiguo patricio de gran entereza moral, pero tan idealista como ingenuo, don Marcelo Peñalba de Mendoza. Ya en el poder, don Marcelo trata de conjurar el peligro de la inmediata intervención de una potencia acreedora con el sólo poder de su oratoria, hinchada de alusiones a los sagrados principios del honor nacional y el derecho de las naciones libres, mientras a sus espaldas sus sostenedores pactan con el extranjero y comprometen las fuentes de riqueza del país. A un ultimátum del extranjero, don Marcelo responde con un nuevo y más inflamado discurso; y luego renuncia. Un nuevo militar sube al gobierno. Don Marcelo vuelve a su retiro, convencido de que su defensa verbal de los altos principios y su renuncia han sentado un ejemplo de heroísmo cívico.

La crítica al tradicionalismo es demasiado evidente aún en este esquema para necesitar comentarios. Coaybay es un país con grandes riquezas naturales, pero vive en la miseria y de préstamos. Exactamente lo que dijo Alberdi de toda Hispanoamérica hace casi un siglo. Nadie intenta en Coaybay salvar la crisis mediante la explotación de su riqueza y la organización del comercio. El gobierno constituído por un grupo de militares ignorantes y sin escrúpulos, sostenido por las clases privilegiadas, sólo aspira a salvar sus intereses aun al precio de enajenar las riquezas nacionales al extranjero. Para ello cuenta este gobierno, como aliados, la ignorancia y el respeto supersticioso por las fórmulas de sentimentalismo patriótico del propio pueblo, y la fe en la eficacia de los principios abstractos del derecho de unos cuantos idealistas ingenuos. Militarismo, falta de sentido económico, desprecio del trabajo, deshonestidad administrativa, respeto por las fórmulas del legalismo, son, pues, algunos de los males de la tradición que Ramos se ha propuesto exhibir en su novela. ${ }^{1}$ Contra ellos, afirma, sólo hay un remedio: el trabajo, fuente de la dignidad y de la riqueza. Esto es lo que Washington, el personaje más importante de Coaybay, se encargará de decirnos.

Washington ha recibido parte de su educación en los Estados Unidos, donde ha seguido cursos de especialización después de gra- 
duarse de abogado en su patria. A su vuelta a Coaybay, un cambio radical se ha operado en el espíritu del joven. "Venía armado - dice él mismo-, de un vasto, pero definido sistema de revalorización, que resultaba un poderoso disolvente en aquel cuerpo nacional de la vieja colonia española, cuya alotropía republicana dejara intacta en lo más substancial." 2 Los nuevos valores que el joven traía eran, según él, "algo hermético e insignificativo para sus compatriotas: el sentido económico de la historia". " "Yo creo que el problema nuestro - decía en una ocasión a su padre-, no es un problema político, sino un problema económico social. La prioridad del problema económico, en tanto una vez reconocida en toda su extensión, ha de operar milagros. Donde falten conocimientos o verdadera experiencia, que se alquilen los servicios de extranjeros hábiles; ; aunque haya que sacar a concurso, en el extranjero, el cargo de Presidente de la República! Se trata de modernizar y de organizar científicamente este predio patrimonial para obtener de él su máximo rendimiento sin comprometer su porvenir." 4

Washington trató al principio de hacerse oír de sus compatriotas, pero éstos le citaron a Rodó, aludieron al "canibalismo yankee", y acusaron al joven de materialista. Entonces, en espera de mejor ocasión, decidió limitar la aplicación de sus ideas a su propia existencia. Renuncia a su profesión de abogado, que ahora se le antoja parasitaria, y se retira al campo a criar aves de corral y a labrar la tierra. La revolución lo encuentra en su retiro. Invitado por su padre a participar en ella, así explica su negativa: "Cuando un grupo de compatriotas nuestros, sin candidato y sin programa demasiado definido, aparezca entre nosotros dispuesto a combatir la ignorancia, la superstición y el fanatismo religioso; la ignorancia, el empirismo $\mathrm{y}$ las enfermedades predominantes en cuanto a higiene del cuerpo, y -la ignorancia otra vez- el tradicionalismo romántico y trasnochado predominante en nuestra instrucción pública, además de su escasez e ineficacia actual... entonces me verás soldado en fila, sumado incondicionalmente al movimiento." 5

De este modo Ramos se ha servido de Washington para hacer más explícita la crítica al tradicionalismo dilúda en la acción de la novela. Pero el mismo personaje le sirve también para expresar su fe en el trabajo como remedio de los males tradicionales de Hispanoamérica y la afinidad que siente Ramos por un pueblo que ha hecho del trabajo un culto: "Faltan en nuestra patria - dice Washington 
a su padre-, además de la educación cooperativa fundamental, las oportunidades en que ese impulso humano se muestra más frecuentemente cuando hay una ventaja colectiva que obtener mediante el esfuerzo combinado de varios individuos. ¿Tú no crees que esa falta de hábitos y de ejemplos de colaboración, de confianza recíproca, de honradez y desinterés administrativos, influyen grandemente en nuestra aparente impotencia para explotar por cuenta propia las riquezas y oportunidades que nos brinda nuestra patria?"

A pesar de estas convicciones, en un momento de ofuscación Washington abandona su retiro y asesina al tirano. Los acontecimientos que luego siguen lo convencen de que la muerte de un dictador no puede cambiar la suerte de la patria, pues su mal está en las raíces mismas de la vida hispanoamericana. Aprovechando que nadie sospecha de él, huye a los Estados Unidos. Allí cambia de nombre, adopta una profesión manual que le procura desahogo económico y paz, y se casa con una norteamericana. Su entusiasmo por la actitud del pueblo norteamericano, tan poco preocupado de tradiciones o prejuicios de casta, tan habituado al trabajo, a la solidaridad y a la cooperación, le hace renunciar para siempre a Coaybay. A las instancias de su padre, contesta: "¿Qué caso harían de mí mis compatriotas absortos en su erotismo ora sentimental, ora simiesco, aferrados a su concepto romántico de la historia —que constituye todavía la base de todos los medios educativos de la nación, desde la escuela al periódico- abandonando al invasor, ciega e irresistiblemente sus tierras, sus fábricas, sus bancos, sus finanzas y sus medios de transporte, y cayendo cada vez más de empréstito en empréstito, dentro del sistema económico de Norlandia, sin perjuicio de acusar de imperialismo a la mera entidad política de esa gran República, ni dejar de aprestarse cada día, con discursos y leyes, a la 'defensa' de la patria, de la religión, de la lengua, de la raza y de no sé cuántas cosas más? ¿Qué podría hacer en un país como el nuestro, en que tienes forzosamente que explotar a los otros para hacer tu fortuna; en que no encuentras socios, ni dinero, ni confianza, ni empeño para empresas grandes, y las chicas, como en todas partes, no sacan nunca de pobre? Pues aquí he podido hacer dinero sin explotar a nadie. He pagado y pago espléndidos jornales. Muchos de mis obreros han vivido a veces mejor que yo mismo. $Y$ vivo de la confianza de los otros, porque con créditos me levanté de la nada y con créditos desenvolví y sostengo ahora más de la mitad de mi negocio ..." ${ }_{6}$ 
La gran admiración que siente Ramos por los Estados Unidos se explica, pues, por la afinidad que él siente entre su propia filosofía antitradicionalista y la del pueblo estadounidense. Donde mejor se expresa esta admiración es en el Panorama de la literatura norteamericana. En esta obra abundan los paralelos, nada halagadores para nosotros, entre nuestra filosofía de la vida y la de nuestro vecino. $Y$ con gran sentido de justicia, trata de disipar malentendidos, poniendo bien en claro que lo que él admira nada tiene que ver con las aventuras financieras de sus banqueros y capitanes de industria, ni con los esclavistas sureños, sino con el hombre común, el Juan Pueblo, surgido de la mezcla de todas las sangres que constituyen la sangre de Norteamérica, y que con su trabajo y su sentido de solidaridad humana ha creado la grandeza de su patria.

"El gran experimento humano por excelencia", llama Ramos a los Estados Unidos." "Los hombres del norte... echaron los cimientos de una sociedad basada en la conquista de la naturaleza por medio del trabajo personal, de la inventiva humana, el esfuerzo asociado del individuo. $\mathrm{Y}$ en consecuencia, valorizaron a éste pór su acción cooperativa casi exclusivamente... En nuestra América, la lucha fué entre caudillos, que vinieron también a la conquista de la naturaleza, desde luego, pero para quienes el indio formaba parte integrante de la naturaleza." Para estos caudillos, prosigue Ramos, "los indios eran pecadores, infieles e idiotas ... La idea aristotélica del esclavo natural, tomando por base la pigmentación de la piel y el origen tropical de la raza, además de su infantilismo económico, se acopló fácilmente a la idea anterior de la aristocracia de nacimiento. Y la Iglesia católica, a despecho de ilustres voces disidentes, ayudó a remachar esos funestos principios combinados en las mentes de los americanos jóvenes. Tenían para ello nada menos que el sistema mismo de la enseñanza. Y a la inicua explotación del indio siguió la del esclavo. Mi más firme creencia - como más de una vez habré dejado traslucir a lo largo de este estudio- es que en esa persistencia de la degradación del trabajo constructivo - del trabajo humano por excelencia, porque sólo el hombre superior, el superhombre, lo posee- reside el vicio radical de nuestra civilización hispánica en América". 8

Se acusa, dice Ramos en otra ocasión, a los Estados Unidos de un "descarnado pragmatismo" contrario al idealismo hispano; pero este pragmatismo "lleva siempre consigo un impulso de renovación, 
de actividad creadora, de humanidad en devenir, mientras nosotros, con ese idealismo que nos atribuimos -y que sólo se refleja en nuestro interminable legislar- vivimos como a rastras, empeñados en resolver nuestros problemas en las próximas elecciones presidenciales, cambiando tierras por chalets, automóviles y menciones en la crónica elegante, y comprando billetes de loteria... y educando a nuestros hijos para ricos, para socialmente 'mejores' como en la época de los príncipes, sin la menor idea de su valor y significación social". 9

También se acusa a los Estados Unidos de imperialismo, dice luego Ramos; pero se olvida que lo que realmente representa a este país no es "el oro maldito de sus empréstitos y sus vampiresas inversiones politico-industriales", ni "la ambición de sus esclavistas sureños". Por lo que ha de juzgarse a este país es por el admirable esfuerzo de su gente común y de sus mejores espíritus, estadistas, creadores y filósofos, "para hallar un establecimiento mejor del hombre en la sociedad, con un mínimo de injusticia y de dolor". 10

La afinidad que Ramos siente por los Estados Unidos no se limita, pues, a su filosofía colectiva, sino también a la de sus mejores espiritus. "Ellos nos hablan -dice- nuestro propio lenguaje a nosotros los coloneses que nunca vendimos a nuestros hermanos, que nunca ejercimos influencia alguna en los 'gangs' gubernativos de nuestros pueblos ..."11 Y en efecto, hay gran afinidad entre la filosofía antitradicionalista y valorizadora del trabajo del escritor cubano y la de los pragmáticos e instrumentalistas norteamericanos. No creo, sin embargo, que debe interpretarse esta afinidad como influencia, pues se necesitaría la pericia lógica de un filósofo profesional unida a la fantasía de un creador para transmutar en materia artística la abstracta teoría del pragmatismo o del instrumentalismo. Ramos no fué filósofo, sino novelista y dramaturgo; y es poco probable que haya llegado a su visión de la realidad hispánica a través de la lectura de filósofos. El antitradicionalismo de Ramos y su apología del trabajo han de haber sido anteriores en su pensamiento a toda influencia del pragmatismo o del instrumentalismo, aunque es posible que estas filosofías hayan contribuído después a afianzar sus convicciones.

Con el pragmatismo de James hay clara afinidad en el pensamiento de Ramos. La crítica del escritor cubano a las ideas consideradas absolutas por la tradición hispánica tiene una base epistemo- 
lógica semejante al criterio de la verdad pragmática. Como James, Ramos prueba la verdad o falsedad de un principio, considerado absoluto, por las consecuencias que de tal principio derivan para los valores de una cultura. $Y$ así Ramos rechaza como falsos los principios de la tradición hispánica por las funestas consecuencias que ellos acarrean para la dignidad del hombre en Hispanoamérica. También hay gran afinidad entre el pensamiento de Ramos y el instrumentalismo de Dewey. Pero, de nuevo, no creo que convenga hablar de influencia de las ideas del gran instrumentalista en Ramos. La mayor parte de la obra de Dewey fué por mucho tiempo demasiado abstracta, contradictoria y difícilmente escrita, para que un novelista pudiera usarla en sus libros. Sólo posteriormente, y cuando la obra de Ramos está ya escrita, aparecen los libros más accesibles de Dewey. Hay uno entre estos últimos, The Quest for Certainty, que contiene ideas extraordinariamente afines a las de Ramos, pero muy posterior a sus novelas, y que debe haber contribuido en no poco a afianzar en el cubano su fe en la dignidad del trabajo productivo. En aquella obra Dewey critica la tradicional tendencia a considerar las actividades prácticas, y por supuesto, el trabajo, como inferior a las llamadas actividades del espíritu, y atribuye dicha tendencia a una primitiva asociación psicológica entre las primeras y la inseguridad o el peligro en la lucha por la existencia. Y como Ramos, Dewey rechaza enérgicamente la jerarquía tradicional entre el pensamiento y la acción, colocando a esta última a la cabeza de las actividades humanas, como madre de las ciencias y de la dignidad del hombre.

No creo que se necesite insistir demasiado para recordar lo que nos ha sugerido la lectura de Ramos. Su filosofía es simple e incisiva. Ella se reduce a combatir el tradicionalismo hispanoamericano y a elevar el trabajo al rango de creador de solidaridad y de dignidad entre los hombres. Su admiración por el pueblo de los Estados Unidos y por sus mayores filósofos no tiene otra razón que el hecho de que en la actitud ante la vida de los primeros y en los sistemas de los últimos, él encontró amplia confirmación para stt propia filosofía. ${ }^{12}$

Manuel Olguín, University of California, Los Angeles. 


\section{NOTA S}

1 En sus otras novelas, Caniqui, Humberto Fabra y Las impurezas de la realidad, Ramos critica estos mismos rasgos de la tradición hispanoamericana y otros a que aludimos al comienzo de este trabajo. Sin embargo, el aspecto constructivo de la filosofía de Ramos no es tan evidente en estas novelas como en Coaybay.

2 Coaybay, p. 134.

3 pp. 134-5.

4 p. 113.

5 Coaybay, p. 109.

6 Coaybay, pp. 348-9.

7 Panorama, p. 6.

8 Panorama, pp. 39-40.

9 Op. cit., p. 71.

10 Panorama, p. 71.

11 Op. cit., p. 239.

$12 \mathrm{Me}$ es grato expresar mis agradecimientos al profesor Manuel Pedro González, amigo dilecto de Ramos y profundo crítico de su obra, por su valiosa asistencia. 
